\title{
Bone Marrow and Extramedullary Involvement
}

National Cancer Institute

\section{Source}

National Cancer Institute. Bone Marrow and Extramedullary Involvement. NCI

Thesaurus. Code C122602.

A finding indicating the involvement of the bone marrow and other anatomic sites, which

may include the peripheral blood, lymph nodes, and/or extranodal sites, by a

hematopoietic neoplasm. 